Volume 1, Issue 2, Nov. - 2020: pp: 53-57 www.ejor.sohag-univ.edu.eg

Original article

\title{
EVALUATION OF PERCUTANEOUS REPAIR OF THETENDON ACHILLES
}

\author{
Mostafa Hemaid $^{(*)}$, Abd-El-Rahman Hafez, Ahmad Addosoki, Hossam Elazab \\ Tauma and Orthopedic Surgery dept., Faculty of Medicine, Sohag Univ., Sohag, Egypt \\ *E-mail: Mustafahemaid@gmail.com
}

\begin{abstract}
The Achilles tendon is the largest and strongest tendon in the body. When the calf muscles flex, the Achilles tendon pulls on the heel. Percutaneous method gives the chance to do sufficient repair of tendon Achilles with minimal slit incisions. Achilles tendon rupture surgery is now routine and well established. Surgery is suggested for young, healthy and active individuals. Percutaneous repair of the Achilles tendon allows accurate opposition of the tendon ends minimizing surgical incision thus protecting against wound breakdown. It is a prospective study of 20 adolescent patients with cut tendon Achilles treated Percutaneous repair using Esipond 5 and Mayo needle, admitted in Orthopedics and traumatology department Sohag university hospital, between 12 / 2017 and 12 / 2018. The patients were followed up for 12 months according to the Achilles tendon rupture score (ATRS) from all patients and by checking wound complications. Limitation due to decrease in the strength of calf/Achilles tendon/foot, the mean score was 8.1. Limitation due to progressive tiredness in the calf/Achilles tendon/foot, the mean score was 8.1. Limitation due to stiffness in the calf/Achilles tendon/foot, the mean score was 8. Limitation due to pain in the calf/Achilles tendon/foot, the mean score was 8. Limitation during activities of daily living, the mean score was 7.7 Limitation when walking on uneven ground The mean score was 7.9 Limitation when walking quickly up stairs or uphill The mean score was 7.95. Limitation during activities that including running, the mean score was 7.9. Limitation during activities that including jumping, the mean score was 7.9. Limitation in performing heavy physical work, the mean score was 8.1
\end{abstract}

Keyword: Achilles tendon rupture, Complications, Infection, Minimally invasive surgery

\section{Introduction}

The Achilles tendon is the primary plantar flexor of the ankle and the strongest tendon in the body [1]. The Achilles rupture most commonly occurs in the third to fourth decade of life, specifically in males, with an annual rate of 18 to 37 cases per 100,000 individuals [2]. Non-operative management is associated with re-rupture rates of $13 \%$ to $33 \%$. The operative treatment has the benefit of early mobilization, lower re- rupture rates, and earlier return to sports practice [3] but the wound complication rate related to surgical management varies from $0 \%$ to $22 \%$ [4]. Although the percutaneous treatment decreases wound complication rate, sural nerve injury rate increases as high as $16.7 \%[5,6]$. Tendon repair using the Krackow suture has been successful regarding the early range of motion and stable fixation [7]. However, percutaneous 
repair proved to be biomechanically stronger than traditional Krackow repairs in cadaver studies [8]. A new modification of a minimally invasive approach using the gift box technique would result in

\section{Materials and Methods}

It is a prospective study of 20 adolescent patients with cut tendon Achilles treated using percutaneous repair technique using Esipond 5 and mayo needle. Admitted

\subsection{Patient selection}

Inclusion criteria: Patients complaining of cut tendon Achilles wound less than $2 \mathrm{~cm}$ with no soft tissue laceration and Patients complaining of rupture

\subsection{General characteristics of patients}

Our study included 20 patients with age ranged from 10 to 50 years old they were divided into 17 males and 3 females, mechanism of injury was 15 patients injured by sharp objects, 3 patients had rupture tendon Achilles in practicing sport

\subsection{Surgical technique}

Before the operation, the rupture site was located by physical examination followed by mapping the tendon and site of incisions. Three slit shaped incisions are done medial and lateral to the proximal portion, two slit shaped incision are done medial and lateral to the distal portion. Esipond 5 is used with Mayo needle. The proximal portion is captured by a suture passed transverse the $1^{\text {st }}$ proximal slits, then suture is crossed to the $2^{\text {nd }}$ proximal slits and to the $3^{\text {rd }}$ proximal slits. Suture is crisscrossed through the gap to capture the distal portion of the tendon and sutures are passed through the distal slits with minimal wound complications. This article aimed to study the clinical and functional results of acute Achilles tendon injury repair using percutaneous technique.

in orthopedics and traumatology department Sohag university hospital, between 12/2017 and 12/2018. An informed written consent was obtained from all participants.

tendon Achilles. Exclusion criteria: Patients with crushed ankle and patients with extensively lacerated wound

and 2 patients due to falling from height. Recording to co morbidities 5 patients had diabetes mellitus and 9 patients were smoking. 11 patients had left tendon injures, 9 patients had right tendon injuries.

the same technique mentioned above. The suture is tied above the calcaneous in plantar flexion. Post-operative below knee cast in equinus is done without weight bearing for one month, then cast in neutral position is done with weight bearing for one month, then cast is removed and physical therapy is begun. Patients are followed up after 2 weeks to check the wound, 2 weeks to modify the cast, one month to remove cast and start weight bearing and physiotherapy, then every 3 months to assess function till one year after surgery, figs. $(1,2,3,4)$

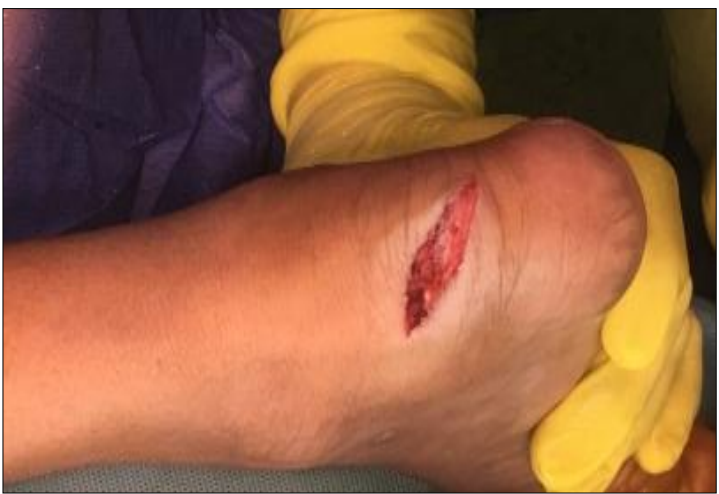

Figure (1) Shows locate wound by physical examination then wash the wound 

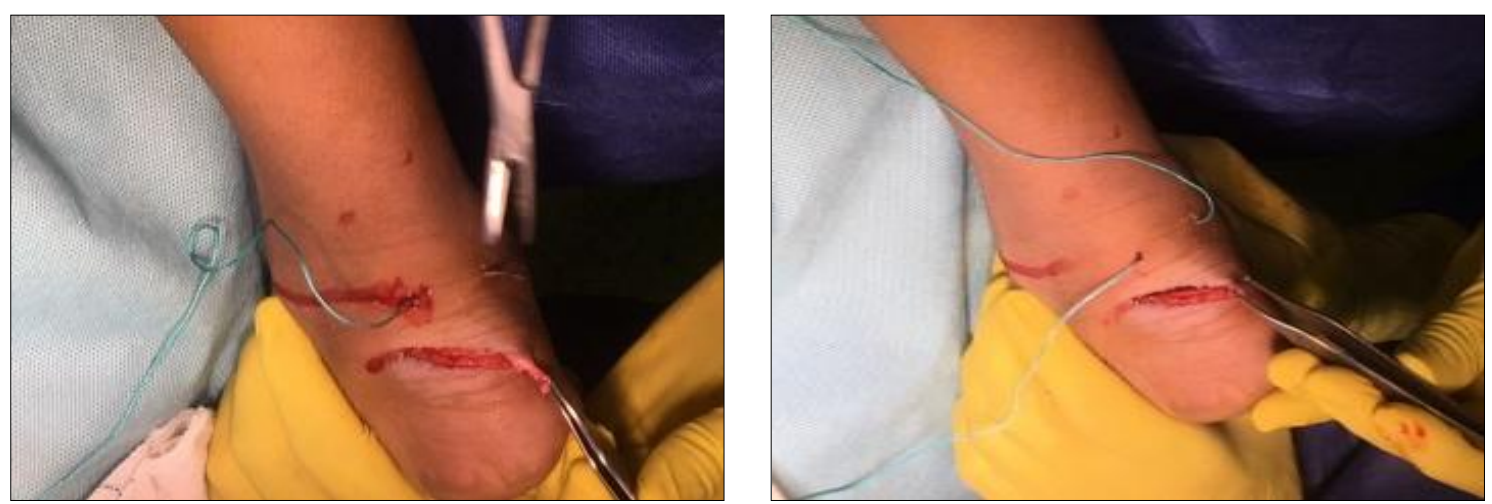

Figure $(2-a, b)$ Show after making 3 slit shaped incisions the proximal portionof the tendon is captured by sutures
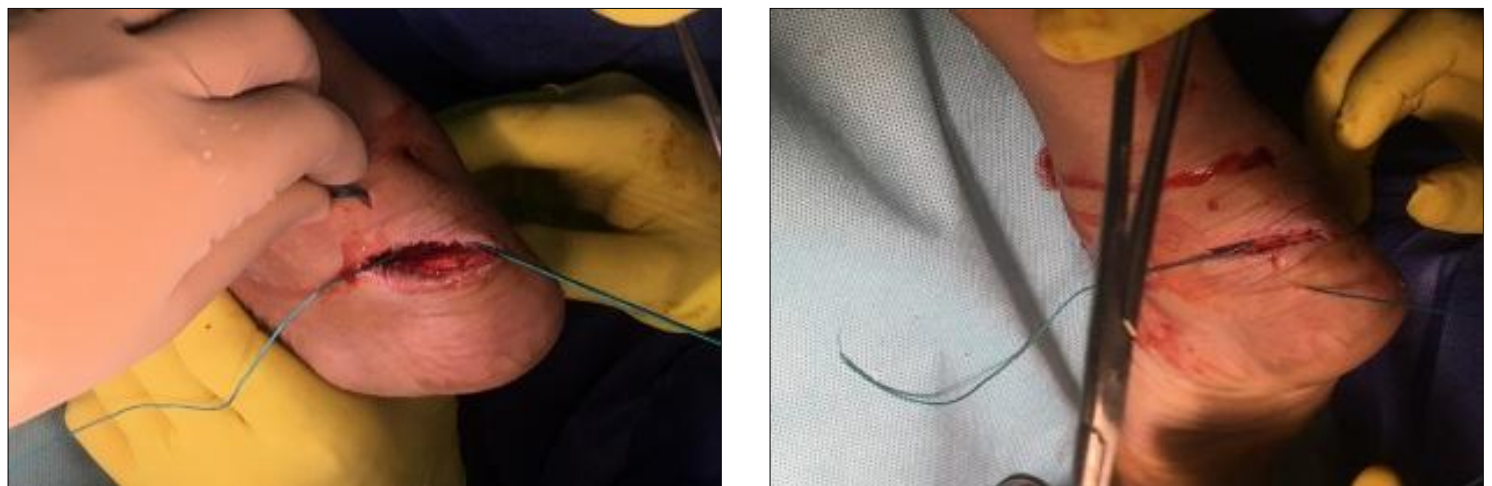

Figure (3-a, b) Show sutures are criscrossed through the gap to attach to the distalportion of the tendon

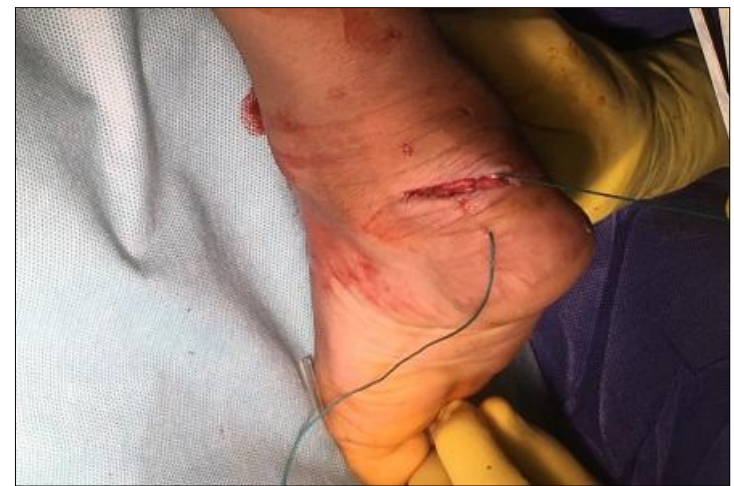

Figure (4) Show sutures are locked distally over the calcaneus then wound is closed

\section{Results}

The outcome of percutaneous repair of tendon Achilles had been estimated using Achilles tendon rupture score, the results are listed in tab. (2). The mean Achilles tendon rupture score is was 80.15. Active maximum plantar flexion and dorsiflexion at follow-up were comparable to the con-tralateral legs. The mean on the affected side was $60^{\circ}$ (range, $20^{\circ}$ dorsiflexion to $50^{\circ}$ plantar flexion) and on the healthy side was $65^{\circ}$ (range, $20^{\circ}$ dorsiflexion to $50^{\circ}$ plantar flexion). There was no limita-tion of eversion and inversion as compared with the contralateral side. The mean in the affected side was $55^{\circ}$ (range, $20^{\circ}$ eversion to $40^{\circ}$ inversion) and on the healthy side was $59^{\circ}$ (range, $20^{\circ}$ eversion to $40^{\circ}$ inversion). Calf circumference was diminished in the injured leg as compared with the contralateral leg in all cases, with a mean atrophy of $8 \mathrm{~mm}$ (range, 7-14 mm). 2 cases complained of wound infection and wound dehiscence, improved on parenteral and oral antibiotics and physiotherapy. 
Table (2) Results of Achilles tendon rupture repair

\begin{tabular}{|l|c|c|c|c|c|c|c|c|c|c|c|}
\hline \multirow{2}{*}{ The case ID } & \multicolumn{9}{|c|}{ Limitation } & \multicolumn{2}{c|}{ Total } \\
\cline { 2 - 13 } & $(1)$ & $(2)$ & $(3)$ & $(4)$ & $(5)$ & $(6)$ & $(7)$ & $(8)$ & $(9)$ & $(10)$ & \multicolumn{2}{|c|}{} \\
\hline No.1 & 8 & 7 & 8 & 9 & 7 & 8 & 9 & 9 & 8 & 10 & $\mathbf{8 3}$ \\
\hline No.2 & 8 & 8 & 8 & 8 & 7 & 9 & 9 & 9 & 7 & 8 & $\mathbf{8 8}$ \\
\hline No.3 & 9 & 9 & 7 & 8 & 9 & 8 & 8 & 7 & 9 & 8 & $\mathbf{8 2}$ \\
\hline No.4 & 9 & 8 & 8 & 8 & 7 & 7 & 9 & 8 & 7 & 9 & $\mathbf{8 0}$ \\
\hline No.5 & 8 & 8 & 8 & 9 & 7 & 9 & 9 & 9 & 8 & 7 & $\mathbf{8 2}$ \\
\hline No.6 & 7 & 8 & 9 & 7 & 8 & 9 & 7 & 8 & 9 & 8 & $\mathbf{8 0}$ \\
\hline No.7 & 7 & 7 & 8 & 9 & 8 & 7 & 8 & 8 & 8 & 7 & $\mathbf{7 7}$ \\
\hline No.8 & 8 & 8 & 8 & 7 & 8 & 8 & 9 & 8 & 7 & 8 & $\mathbf{7 9}$ \\
\hline No.9 & 9 & 9 & 8 & 7 & 8 & 9 & 9 & 8 & 7 & 9 & $\mathbf{8 3}$ \\
\hline No.10 & 9 & 9 & 8 & 7 & 8 & 8 & 7 & 8 & 8 & 9 & $\mathbf{8 1}$ \\
\hline No.11 & 9 & 9 & 8 & 9 & 8 & 7 & 8 & 9 & 9 & 9 & $\mathbf{8 5}$ \\
\hline No.12 & 8 & 8 & 9 & 8 & 8 & 7 & 8 & 8 & 9 & 8 & $\mathbf{8 1}$ \\
\hline No13 & 9 & 9 & 8 & 7 & 8 & 9 & 8 & 7 & 8 & 9 & $\mathbf{8 2}$ \\
\hline No.14 & 8 & 8 & 8 & 9 & 8 & 8 & 7 & 8 & 9 & 8 & $\mathbf{8 1}$ \\
\hline No.15 & 6 & 6 & 8 & 8 & 7 & 6 & 6 & 8 & 7 & 6 & $\mathbf{6 8}$ \\
\hline No.16 & 8 & 8 & 9 & 8 & 7 & 8 & 9 & 8 & 7 & 8 & $\mathbf{8 0}$ \\
\hline No.17 & 9 & 9 & 7 & 8 & 9 & 7 & 7 & 7 & 9 & 7 & $\mathbf{7 9}$ \\
\hline No.18 & 9 & 9 & 8 & 9 & 7 & 8 & 7 & 6 & 8 & 9 & $\mathbf{8 0}$ \\
\hline No.19 & 7 & 7 & 8 & 7 & 7 & 9 & 7 & 7 & 7 & 7 & $\mathbf{7 3}$ \\
\hline No.20 & 7 & 8 & 7 & 9 & 8 & 9 & 8 & 8 & 7 & 8 & $\mathbf{7 9}$ \\
\hline The Mean & & & & & & & & & & & $\mathbf{8 0 . 1 5}$ \\
\hline
\end{tabular}

Limitation1; due to decrease strength, Limitation2; due to progressive tiredness, Limitation3; due to stiffness, Limitation4; due to pain, Limitation5; due to daily activities, Limitation6; due to walking on uneven ground, Limitation7; due to walking quickly up stairs, Limitation8; due to running, Limitation9; due to jumping, Limitation10; due to doing heavy physical activities

\section{Discussion}

Numerous open surgical procedures have been proposed for repairing ruptures of the Achilles tendon, but there is no single, uniformly superior technique. Delayed wound healing, necrosis, suppuration and adhesions are potential complication of open procedures which are not rare especially in diabetic patients and smokers. Open procedures with delayed tendon healing time are not suitable also for athletes wishing to return earlier to their preinjury activity level. Augmented open procedures have to be performed for neglected or defective Achilles tendon ruptures $[9,10]$. In the first, Nilsson-Helander et al. [11] developed and validated the ATRS. The total ATRS ranged from 17 to 100, with a mean of 77. Lim et al. [12] randomized 66 young patients (mean age, 38.5 years; range, 26-53 years) to compare open and percutaneous repair of closed AT ruptures. They had a higher rate of complication in open repair. There were $7 / 33(21 \%)$ wound infections and two reruptures $(6 \%)$ in the open group compared to $3 / 33$ cases of wound puckering $(9 \%)$, one rerupture (3\%) in the percutaneous group. They advocated percutaneous repair on the basis of the low rate of complications and improved cosmetic appearance. Given these findings, we also advocate percutaneous repair in older patients with AT rupture to minimize the rate of infections arising from traditional open repairs [13]. Our data suggest that percutaneous repair under local anesthesia for acute AT ruptures in patients older than 65 years gives good results in terms of postoperative ATRS, maximum calf circumference, and isometric plantar flexion strength. 


\section{Conclusion}

Percutaneous repair of tendon Achilles using three proximal mini-incisions and two distal incisions offers good functional and clinical outcomes without wound complications which can be usually observed following open repair of AT ruptures.

\section{References}

[1] Weinfeld, S. (2014). Achilles tendon disorders. Med Clin North Am. 98 (2): $331-338$

[2] Bruggeman, N., Turner, N., Dahm, D., et al. (2004). Wound complications after open Achilles tendon repair: An analysis of risk factors. Clin Orthop Relat Res. 427 (1): 63-66.

[3] Cetti, R., Christensen, S., Ejsted, R., et al. (1993). Operative versus nonoperative treatment of Achilles tendon rupture: A prospective randomized study and review of the literature. $\mathbf{A m}$ J Sports Med. 21 (6): 791-799.

[4] Bhandari, M., Guyat,t G., Siddiqui, F., et al. (2002). Treatment of acute Achilles tendon ruptures: A systematic overview and meta-analysis. Clin Orthop Relat Res. 400 (1): 190-200.

[5] Khan, R., Fick, D., Keogh, A., et al. (2005). Treatment of acute Achilles tendon ruptures: A meta-analysis of randomized, controlled trials. J Bone Joint Surg Am. 87 (10): 2202-2210.

[6] Buchgraber, A., Passler, H. (1997). Percutaneous repair of Achilles tendon rupture: Immobilization versus functional postoperative treatment. Clin Orthop Relat Res. 341 (1): 113-122.

[7] Krackow, K., Thomas, S., Jones, L. (1988). Ligament-tendon fixation: Analysis of a new stitch and comparison with standard techniques. Orthopedics. 11 (6): 909-917.

[8] Labib, S., Rolf, R., Dacus, R., et al. (2009). The "Giftbox" repair of the Ach-

illes tendon: A modification of the Krackow technique. Foot Ankle Int. 30 (5): 410-414.

[9] Chan, K., Lui, T., Chan, L. (2009). Endoscopic-assisted repair of acute Achilles tendon rupture with Krackow suture: An anatomic study. $\boldsymbol{J}$ Foot Ankle Surg. 15 (4): 183- 186.

[10]Metz R, van der Heijden GJ, Verleisdonk EJ, Tamminga $R$, van der Werken C. Recovery of calf muscle strength following acute Achilles tendon rupture treatment: a comparison between minimally invasive surgery and conservative treatment. Foot Ankle Spec. 2009;2:219-26. doi: $10.1177 / 1938640009348338$.

[11] Nilsson-Helander, K., Thomee, R., Gravare-Silbernagel, K., et al. (2007). The Achilles tendon Total Rupture Score (ATRS): Development and validation. Am J Sports Med. 35: 421426.

[12]Lim, J., Dalal, R., Waseem, M. (2001). Percutaneous vs. open repair of the ruptured Achilles tendon-a prospective randomized controlled study. Foot Ankle Int. 22: 559-568.

[13] Nestorson, J., Movin, T., Moller, M., et al. (2000). Karlsson J. Function after Achilles tendon rupture in the elderly: 25 patients older than 65 years followed for 3 years. Acta Orthop Scand. 71: 64-68. 